\title{
HEAT TRANSFER ENHANCEMENT AND SURFACE THERMOSTABILIZATION FOR POOL BOILING ON POROUS STRUCTURES
}

\begin{abstract}
Tadeusz Michal WOJCIK•
Abstract: The scope of the article includes the description of the experimental setup, methodology of the experimental studies, the study results for pool boiling heat transfer coefficient encountered on sintered capillary porous coverings. The results of own studies presented here refer to the boiling in a large volume on copper fibrous coverings. Hysteresis type I, II and III were described. Several examples of capillary porous surface coverings applications in purposely chosen complex boiling heat transfer processes have been presented based on Wojcik and Poniewski patents.
\end{abstract}

\section{INTRODUCTION}

Transferring large heat fluxes is one of the most significant issues of today's technology and results from the rapid development of electronics, nuclear, space, military and medical technologies, and various others. The growing computing power of processors increases the amount of heat and forces extensive cooling. Heat transfer on a flat surface, even at boiling, has become insufficient. There is an urgent need for new solutions.

In years 1995-2009 the author and co-workers conducted comprehensive research related to heat transfer for pool boiling on extended surfaces. The studies included experimental and theoretical investigations, developing technologies and the issues of lab-scale manufacturing of sintered porous structures (both metal, fibrous and new complex ones worked out by the author and co-workers), as well as application-related problems such as the use of a boiling process in heat transfer control.

\section{Boiling Heat Transfer on Porous Structures}

Fig.1 shows the heat transfer characteristics on a flat horizontal surface at pool boiling (dotted line) and the postulated characteristics (solid line), expected as a result of the heating surface modification. The lines illustrate the course of changes in heat transfer coefficient $a$ as a function of heat flux $q$.

The set of properties that make the heat transfer characteristics on modified surface different from that of flat surface include:

- increased heat transfer coefficient within the entire boiling heat transfer regime,

- the shift towards the lower temperatures of the heating surface at the onset of nucleate boiling,

- increased heat flux value for nucleate boiling crisis and its smoothed course,

- stable course of $q=q(a)$ characteristics, both at increasing and decreasing heat flux.

\footnotetext{
•AGH University of Science and Technology, al. Mickiewicza 30, 30-059 Cracow, Poland, tmwojcik@agh.edu.pl
} 


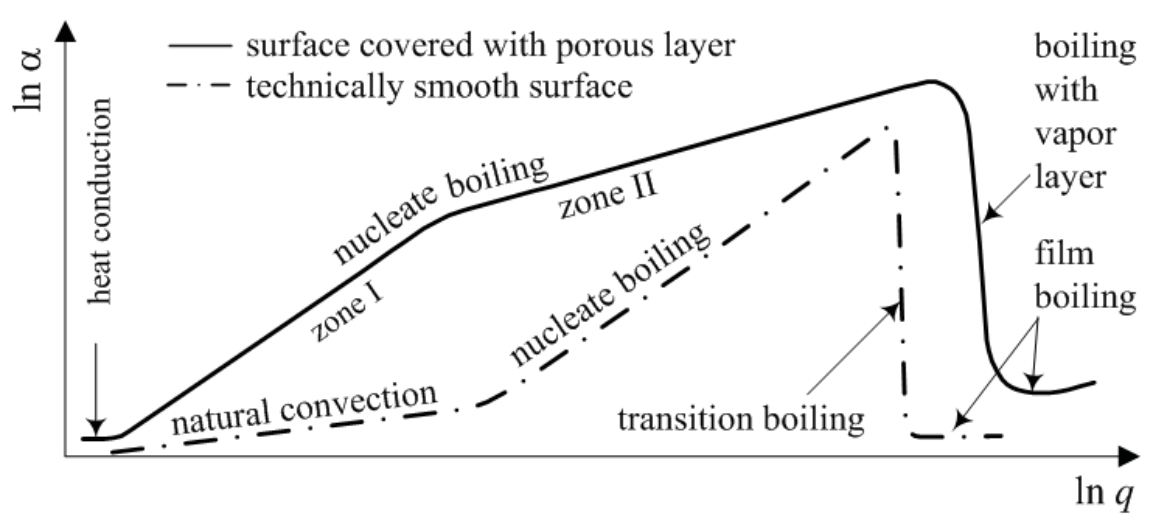

Figure 1: Correlation between heat transfer coefficient $a$ and heat flux $q$ in pool boiling [1]

Copper, fibrous, capillary-porous structure is a layer of wires (fibers) sintered with one another and with the heating surface, Fig.2. Main structural parameters of the coatings, most often made of copper or stainless steel, include: diameter of the wire $d_{f}$, its length $I_{f}$, porosity of the layer $\Pi$ and its thickness $\delta$. The parameters vary in the following ranges: $d_{f}=10 \div 100 \mu \mathrm{m}, I_{f}=1 \div 10 \mathrm{~mm}, \Pi=0.40 \div 0.85, \delta=0,2 \div 2 \mathrm{~mm}$. For the metal, fibrous sintered coatings, the thickness and porosity of the layer can be obtained as planned, unlike in other methods, for instance, in the thermal spraying technique. In own studies, the authors used copper, sintered structures with the following parameters: $d_{f,}=$ $50 \mu \mathrm{m}, l_{f}=3 \mathrm{~mm}, \Pi=0.40 \div 0.85, \delta=0,2 \div 2 \mathrm{~mm}$.

Metal, fibrous porous coverings with planned structural parameters, which determine their heat transfer properties, are used for the construction of heat transferring surfaces in industrial applications.

The experimental setup is shown in Fig.3. The stand allows measuring heating surface superheats exceeding the saturation temperature of the working liquid - $\Delta T$, for the given heat flux $q$ and recording the process of bubbles generation and departure. A specimen with a porous covering was mounted on a copper cylinder. A heater wound around the cylinder was charged via autotransformer. Type $\mathrm{K}$ thermocouples were mounted underneath the specimen, on the axis of the cylinder and in the boiling liquid. The temperature of the heating surface was determined by extrapolating to it temperatures measured along the axis of the cylinder.

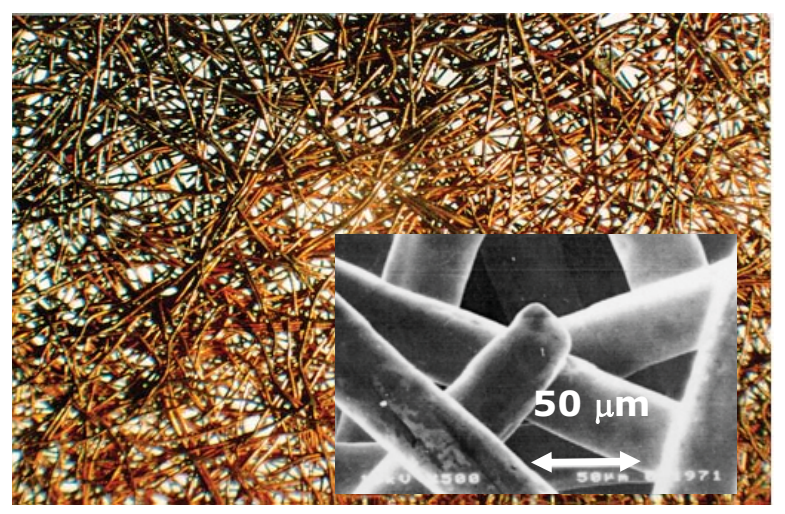

Figure 2: Metal, fibrous porous structure 


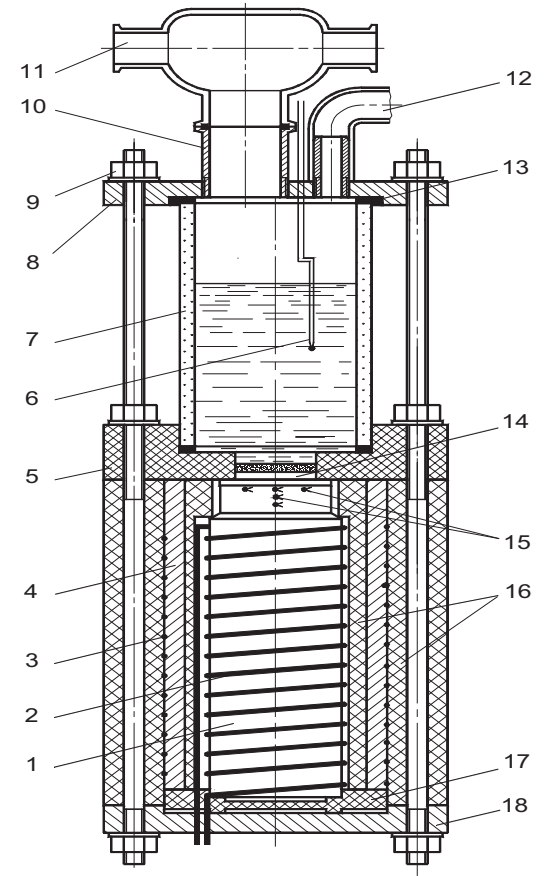

Figure 3: The main module of the experimental apparatus: 1-copper block 2-main heater 3 - compensation heater 11 - condenser 14 - specimen with capillary - porous structure 15,6 - thermocouples

\section{EXPERIMENTAL RESULtS}

Fig. 4 presents the sample results of the heat transfer coefficient measurements obtained for the nucleate boiling of water. The results of the experiments confirmed a significant effect of porous structure parameters on the heat transfer intensity.

Porous coatings have a disadvantage consisting in their tendency to instability, which shows as a non-explicit course of boiling curves at the increase and decrease in the heat flux. The ambiguities occur in the form of heat transfer hysteresis phenomena.

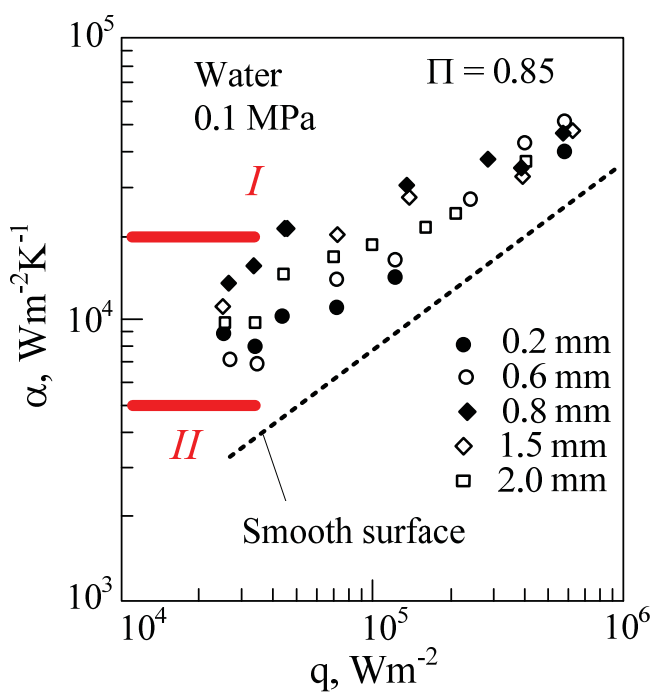

Figure 4: Example of the dependence of the heat transfer coefficient $a$ on the heat flux $q$ for the structures with variable porous coating thickness, $\alpha_{I} / \alpha_{I I} \sim 5$ 
The applied experimental procedure enabled to distinguish three typical boiling curves with hysteresis, namely:

- type I, Fig.5a; - type II, Fig.5b; - type III, Fig.5c [2].

\section{Application Issues}

In our investigations it was assumed that the copper coating with an addition of the copper oxide powder would generate pores resulting from the diffusion, which in turn should lead to the extension of the surface inside the structure and provide additional nucleation sites with the set size distribution.
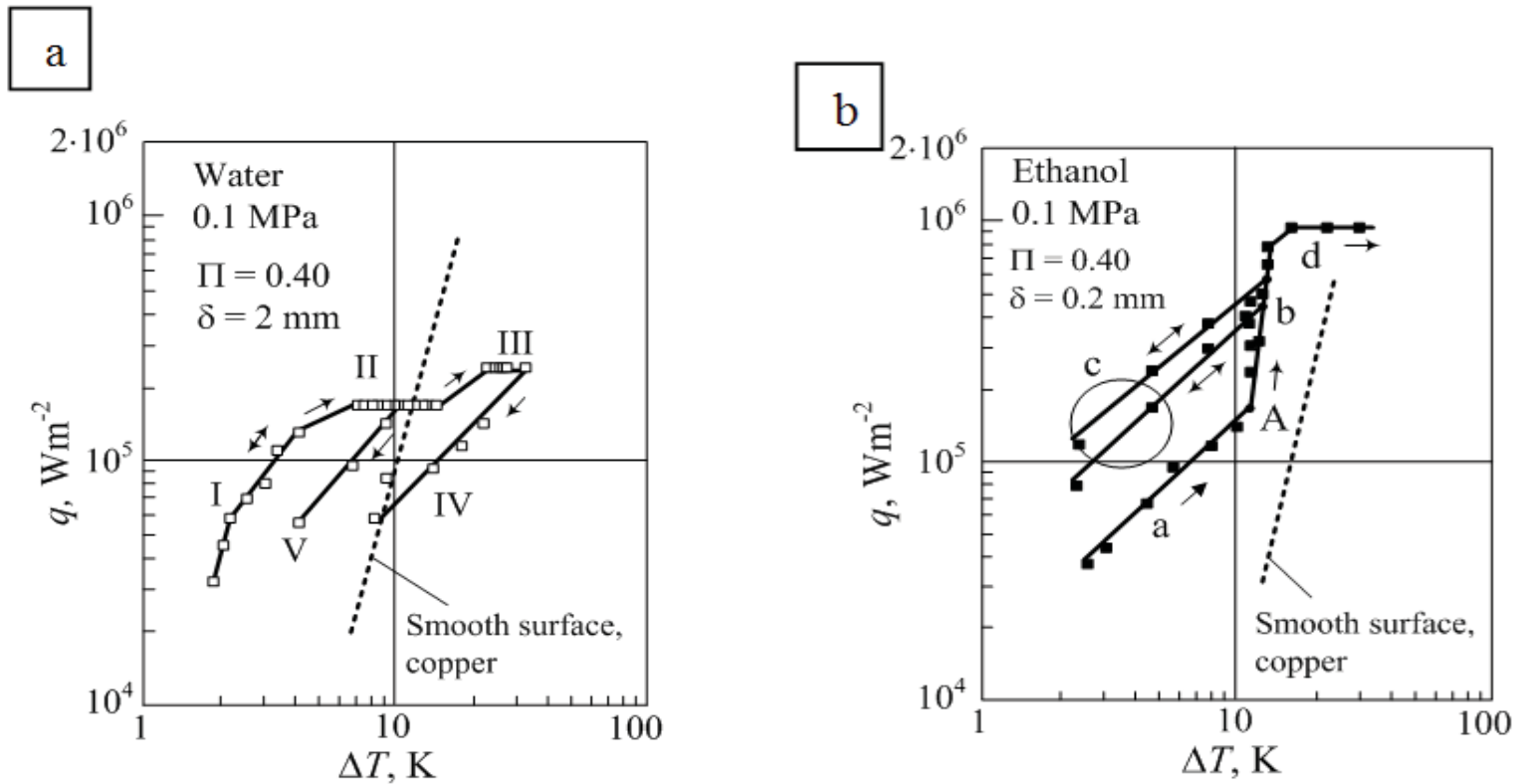

c

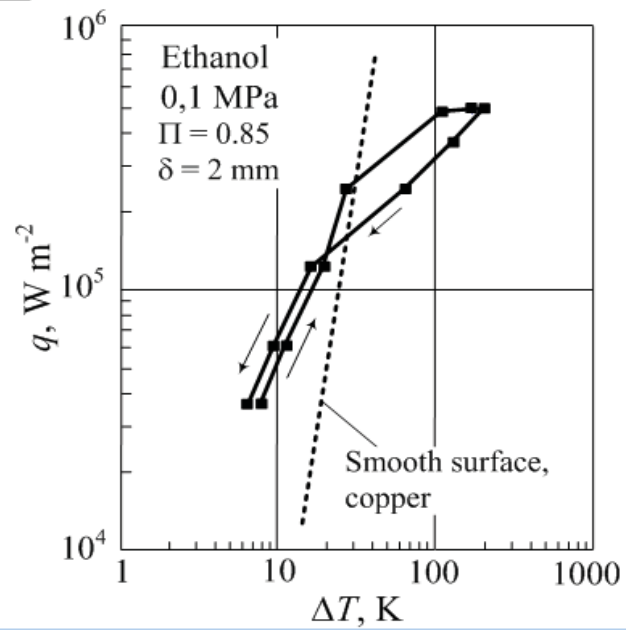

Figure 5: Examples of heat transfer hysteresis:

a-type I;

b-type II;

c- type III 
It gave the impulse to the authors to start works on manufacturing new capillary porous coatings for heating surfaces, with purposely set structural parameters. The copper powder with particles of $\sim 50 \mu \mathrm{m}$ in diameter and cuprous oxide powder particles remained within the range of $80 \div 200 \mu \mathrm{m}$ were used in the experiment. A considerable heat transfer enhancement has been achieved, which is confirmed by the relationship of heat transfer coefficients for surfaces coated with new porous layer, Fig.6, to the coefficient for the smooth surface, which reached its maximum value of 11.5 for ethanol as the boiling liquid.

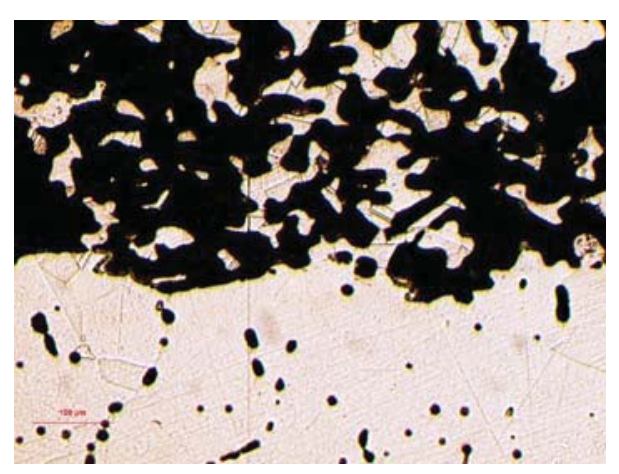

Figure 6: New porous covering

Stability and repeatability of the curves for boiling with type-II hysteresis help present a new approach to boiling heat transfer control on heating surfaces coated with porous layers. Those two features of type-II hysteresis decide about its name "controlled hysteresis". The described phenomenon can find applications in the control of heating surface temperature. The heat source, to which the control refers, is cooled with the use of boiling process on the surface coated with CPS. The structure characteristics are selected in such a way that it is possible to achieve type-II hysteresis similar to that presented in Fig.5b. The technique of control is presented in Fig.7. At the unwanted change in the heat flux emitted by the source (for instance from $q_{1}$ to $q_{2}$ ), it is possible to find such point $\boldsymbol{B}$ on the curve $\boldsymbol{b}$ that after the next heat flux decrease to the set value, the constant temperature difference of the heating surface and liquid saturation $\Delta T_{n}$ can be obtained. This requires that an additional heat source emitting heat flux $q_{a d}$ is used for the time necessary to reach point $\boldsymbol{B}$. The procedure of heat transfer surface temperature control has been patented [3].

The heating surface temperature equalization for the case presented in Fig. 8 is shown in [4]. The patent has used the dependence of the heat flux on the superheat, and porous coating porosity and thickness Fig. 8 presents the parameters of the coating (porosity, thickness) which allow maintaining constant temperature of the surface for the variable flux. 


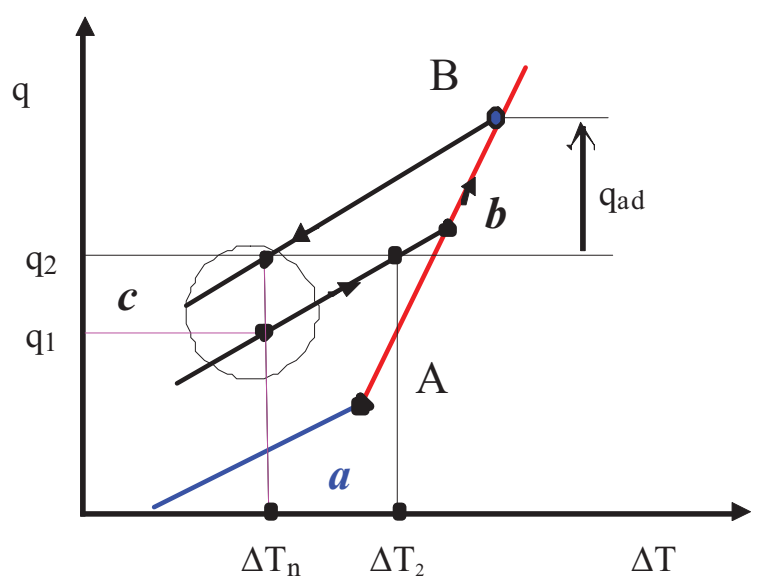

Figure 7: Heat transfer control method

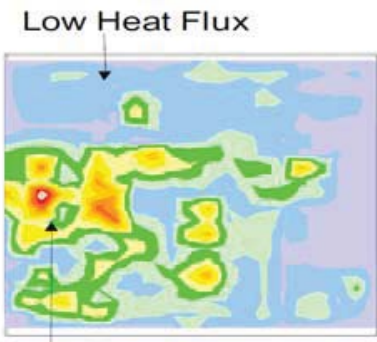

High Heat Flux
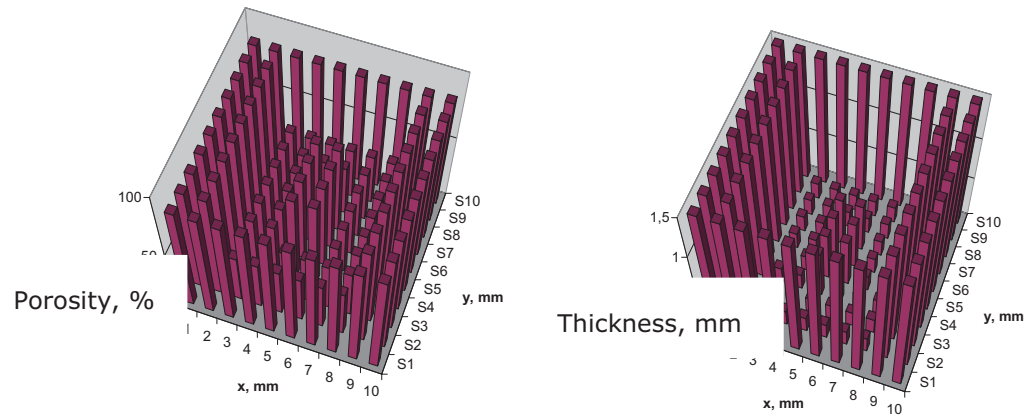

Figure 8: Application of capillary-porous structure to equalization of computer processor temperature [4]

\section{RefERENCES}

[1] Semena M.G., Geršuni A.N., Zaripov V.K.: Teplovye truby s metallovoloknistymi kapiljarnymi strukturami, Višča Škola, Kiev, 1984 (in Russian)

[2] Wójcik T.M.: Experimental investigations of boiling heat transfer hysteresis on sintered metal - fibrous structures, Int. J. Thermal and Fluid Science, vol.33, 2009, pp.397-404

[3] Patent P-176683, Afanasjew B.A., Poniewski M. E., Wójcik T. M: Method for heat transfer control, Polish Patent Office, Warszawa, 1999 (in Polish)

[4] Patent P-379266, Wójcik T.M., Poniewski M. E.: Method for temperature reduction and equalization on the heat transfer surface under varied thermal loads, Polish Patent Office, Warszawa, 2008 (in Polish) 